\title{
Intentional Application of the Taba Curriculum Model to Develop a Rural Pharmacy Practice Course
}

Edward Portillo, PharmD; Kevin Look, PharmD, PhD; Dave Mott, PhD, FAPhA, RPh; Robert Breslow, RPh; Mara Kieser, MS, RPh; Casey Gallimore, PharmD, MS

University of Wisconsin-Madison School of Pharmacy

\begin{abstract}
The changing profession of pharmacy demands student preparation in dynamic courses that address the evolving healthcare landscape. Identifying an evidence-based approach to develop such coursework and content, however, can be a considerable challenge for curriculum innovators. This manuscript explores how curriculum design models can be applied as a guide to promote purposeful development of new curriculum, with the goal of promoting students as APPE, practice, and career-ready practitioners. Authors specifically describe a case study example for the process of creating a novel rural health course using the Taba curriculum design model as a guide for selecting course content, objectives, teaching strategies, learning experiences, and evaluative measures. Through the incorporation of the Taba model, this manuscript presents an evidence-based approach to curriculum development which can be replicated across schools and colleges of pharmacy. The described approach to curriculum design, which integrates models to guide the creative process, is a systematic approach to developing curriculum with purpose. Additional opportunities exist for curriculum innovators across the academy to explore incorporation of curriculum design models to guide course development, as well as to drive curricular assessment strategies and further curriculum refinement.
\end{abstract}

Key Words: curriculum theory; Taba model; curricular design

\section{The Innovation and Its Importance}

Schools and Colleges of Pharmacy are uniquely positioned to positively influence the future of pharmacy practice through innovation in curriculum design that sparks student growth and development. Novel teaching strategies and approaches such as flipped classrooms, blended learning, and authentic assessment techniques, have been linked to improvements in health science student graduation rates, student quality of life, attitudes, and confidence applying didactic content. ${ }^{1-5}$ However, despite the known benefits associated with many instructional innovations, the process of selecting and structuring the right mix of innovations within a course or curriculum can be challenging. In other words, identifying strategies and activities for content delivery that achieve desired objectives, while providing a positive learning experience for students, can be daunting without appropriate guidance or direction regarding curricular design.

The importance of curriculum design is well described in Accreditation Council for Pharmacy Education (ACPE) Standard 10 , which challenges the academy to develop curricula that impact student attitudes, behaviors, and content integration throughout the program's duration. ${ }^{6}$ Still, the process of curriculum design and assessment may leave educators with more questions than answers, and such uncertainty can further complicate the already challenging task of innovating to develop novel educational experiences for students. Instructors may find themselves asking, how do I align curricula with the needs and wants of the program? How do I select appropriate

Corresponding author: Ed Portillo, PharmD

University of Wisconsin-Madison School of Pharmacy

Email: Edward.Portillo@wisc.edu content and then organize, structure, and deliver information in a manner that meets desired objectives? How do I evaluate curricular innovations to understand if they are meeting the desired goals? One method to systematically explore answers to these questions is through the application of a curriculum design model. In the most basic sense, curriculum models are representations of how a curriculum should be structured or processes for thinking about a curriculum. ${ }^{7}$ There are a wide array of curriculum models that serve a variety of purposes and uses, ranging from guiding institutions in reaching consensus on curricular goals and objectives, to problem solving curricular issues, to designing curricular plans, to any combination of the former. ${ }^{7}$

This manuscript provides a case illustration describing the application of a curriculum design model in the development of a rural health elective course. The Taba Model for curriculum design was specifically selected and applied from idea conception through design and launch of the new course to demonstrate how a curriculum design model can serve as a guiding framework for curriculum advancement in pharmacy education. The Taba model, first proposed by Hilda Taba, is considered a highly influential method for curriculum design that continues to inform the development of activities, courses, and programs to this day. ${ }^{8}$ Hilda Taba's work is well described in the literature emphasizing methodological approaches to curricular design in higher education, and has been applied in a variety of educational settings to help instructors understand the needs of the learner and structure objectives and activities to meet these needs. ${ }^{9-11}$ In health care education, the works of Hilda Taba are described in the nursing education literature to guide transition to a curriculum with greater emphasis on teaching concepts rather than recollection of facts. ${ }^{12,13}$ Given the broad applicability of the Taba model, examples are also 
available outside of healthcare education. ${ }^{14,15}$ However, no examples within pharmacy education were identified.

This manuscript will describe the use of the Taba model as part of a process-centered approach to design a curriculum for a rural health elective course to address an identified need within University of Wisconsin-Madison's Doctor of Pharmacy (PharmD) program. It addition, it will share the process and lessons learned from this experience. This manuscript also illustrates methods for identifying, evaluating and refining essential course elements to promote student learning through the use of a curriculum design model.

\section{The Case Example}

The opportunity and need exists for student pharmacists from the University of Wisconsin-Madison School of Pharmacy to pursue a career in rural healthcare given $97 \%$ of the landmass in the state of Wisconsin is rural. ${ }^{16}$ However, while nearly $40 \%$ of students enrolled in the School report coming from a geographic area defined as rural, historically only $17 \%$ elect to return to a rural area to practice post-graduation. A review of the curriculum identified that one potential contributing factor to this disparity was lack of content introducing students to rural health care, including curriculum illustrating the need for pharmacists in rural communities, rural practice opportunities, and available training pathways. Faculty determined that greater integration of rural health content in the curriculum was needed, specifically emphasizing the participation of pharmacists practicing within rural healthcare teams, and the public health role of the pharmacist as a community leader.

To address this curricular need, an interdisciplinary planning workgroup was formed in October 2016, which consisted of five faculty members: three members of the Pharmacy Practice Division and two members from the Social and Administrative Sciences Division. The faculty workgroup chartered a plan to develop a two-year rural health longitudinal program, including didactic, experiential, and co-curricular components. Within the didactic component of the curriculum, faculty determined that a 2-credit course titled Topics in Rural Health Practice was an essential element to provide students the baseline knowledge and skill-set to effectively practice as rural health clinicians. The Topics in Rural Health Practice course is the first didactic course in the students' program and exposes students to foundational elements of rural pharmacy practice. The rural health longitudinal program is optional for students to apply for, and only students enrolled in the program are eligible to enroll in the Topics in Rural Health Practice course. The following sections detail how the Taba model was used to guide the creation of the Topics in Rural Health Practice component of the rural health curriculum.

\section{The Curriculum Design Model}

The Taba Model was first proposed by Hilda Taba in 1971 for use by instructors at the classroom level, and is described in her 1962 novel Curriculum Development: Theory and Practice. ${ }^{17}$
Hilda Taba was an Estonian-born educational theorist in the United States who greatly influenced the ideas of curriculum design in the 1960s-1970s. ${ }^{18}$ The works of Hilda Taba are considered classic curriculum theory and continue to influence new ideas and innovations in curriculum development. ${ }^{18}$ Many of the curriculum design ideas described by Hilda Taba were influenced by her colleague and fellow curriculum theorist Ralph Tyler, who published a curriculum design process in his seminal work titled Principles of Curriculum and Instruction. ${ }^{9}$ While the ideas and concepts surrounding Hilda Taba's curriculum design theory were undoubtedly influenced by Ralph Tyler, Hilda Taba challenged the thinking of curriculum theorists with her flexible, teacher-centered approach. ${ }^{19}$

The model, despite being published in the 1960s, continues to inform curriculum design on a global scale and has influenced curriculum design in the Americas, Europe, and across the globe. $^{20}$ Taba, discussed below, believed that educational strategies should be determined through democratic guidance and partnerships formed by teachers and other thought leaders in the area of study. ${ }^{18}$ Through such a collaborative approach, instructors are positioned to drive curriculum decisions with the needs of students at the forefront. ${ }^{9}$ An approach that emphasizes collaborations and teacher-driven content is applicable in pharmacy education, where content is constantly evolving as health care delivery models continue to advance. In such an environment, the need for shared decision making, collaborations, and fluidity in curriculum design become critical to ensuring a progressive curriculum.

To inform selection of an appropriate curriculum design model for the Rural Heath elective course, a faculty workgroup identified several overarching principles they wanted to remain at the forefront during the design process: 1) engage stakeholders to determine specific knowledge, skills and best practices for pharmacists to be successful in rural practice, 2) use this specific list of knowledge and skills to inform course goals and learning objectives, and 3) engage student learners to determine methods for delivering course content to optimize the learning experience and achieve desired outcomes. The group felt it was important to integrate input from key external stakeholders, such as pharmacists, health system administrators, and professional organizations dedicated to advancing rural healthcare to align course content with the wants and needs of rural communities. The input of key internal stakeholders, such as pharmacy students, faculty, and staff at the School, was also deemed important to ensure information from external stakeholders was integrated in a way that would enhance student learning. Amongst potential curriculum models, the Taba model appeared to support the achievement of these goals given its collaborative, grassroots, and teachercentered approach to classroom design and evaluation.

\section{Application of the Taba Model}

The Taba model considers the following six factors, to guide curriculum design: 1) external factors, 2) content, 3) objectives, 
4) teaching strategies, 5) learning experiences, and 6) evaluative measures. $^{9,10}$ It applies a non-linear approach to curriculum design, meaning components can be developed in any order that best fit the needs of the course or program. Through an inductive approach considering each of these factors, broad overarching teaching themes and generalizations are developed. ${ }^{21}$ The development process for the Topics in Rural Health Practice course, organized according to the components of the Taba model, is shown in Figure 1. The exploratory nature of this approach allows for careful examination of the competencies that are most critical for students to learn and uses these competencies to inform course themes.

Faculty workgroup members met monthly over a 15-month period. Applying the Taba model to course design, core competencies were identified to organize course content and experiences, and learning objectives were developed for each competency. Teaching strategies were selected for the delivery of course material. Finally, a formal assessment plan was developed to assess and inform future iterations of the course considering the achievement of learning objectives, the effectiveness of teaching strategies, appropriateness of course content, and perspectives of stakeholders. In the subsequent paragraphs, each step of course development is described as it applies to the Taba model components.

\section{Content}

Content within the Taba model refers to the core topics or subject matter covered in the course. To flush out potential content areas faculty members explored the specific wants and needs of stakeholders. Specifically, faculty were interested in understanding the current landscape of rural health care and identifying the real-world skill set that would allow pharmacists to complement care provided in rural settings. This was achieved by conducting informal focus groups with key external stakeholders. The first focus group was conducted with 14 pharmacy directors practicing in rural health systems across the state of Wisconsin to better understand the unique challenges and opportunities of rural pharmacy practice. Focus group participants were members of the Rural Wisconsin Healthcare Cooperative advocacy group, which is an organization with the vision of making rural Wisconsin communities the healthiest in America. Feedback from this initial focus group was subsequently presented to the Health-System Pharmacy Advisory Board of the Pharmacy Society of Wisconsin, the Wisconsin state pharmacy association, for additional feedback and confirmation of key themes. This group consisted of 16 members representing health systems across the state of Wisconsin.

The information collected from all external stakeholders was compiled, transcribed and presented to the faculty workgroup. Faculty analyzed the feedback from the focus groups to identify themes to inform the development of specific course content. The focus was placed on isolating competency areas, the key knowledge needed for students to develop a fundamental understanding of rural health care, and the skills needed for entering rural practice.

\section{Objectives}

The Taba model emphasizes the identification of overall objectives by considering a variety of perspectives, which may include, but are not limited to, the needs of the student, discipline, or society. ${ }^{10,17}$ The faculty workgroup considered the perspectives of external stakeholders from the focus groups as well as their own internal perspectives to identify course goals. These goals were the basis for development of learning objectives. Learning objectives were also designed and tailored by the faculty workgroup to align with Accreditation Council for Pharmacy Education (ACPE) Accreditation Standards, and were stratified by Bloom's Taxonomy to reflect various levels of learning required for content mastery.

\section{Teaching Strategies}

The teaching strategies component of the Taba model considers the instructional approaches that are best suited for student engagement with the planned curriculum. ${ }^{10,17}$ Teaching strategies refer to how learning is structured or situated during each class session. The Absorb-Do-Connect learning framework was selected by course faculty to inform teaching strategies and to structure learning within the course in a consistent manner. ${ }^{22}$ While Absorb-Do-Connect is an independent framework to the Taba model, they are complementary in that both emphasize relating course content to real-world examples as critical element to curriculum design. ${ }^{2,3}$ Across each individual class period and longitudinally across the course, teaching strategies were identified that provided students opportunity to absorb key concepts, apply those concepts through actual doing, and connect learning to future practice. Teaching strategies that target the "absorb" level of learning facilitate understanding of key content. Within the rural course "absorb" approaches included pre-class readings or videos and post-class reflections. Teaching strategies within the "do" level of learning provide opportunity for students to advance from understanding to applying knowledge. Fieldwork within a rural community was selected as the primary "do" approach. Finally, teaching strategies targeting the "connect" level of learning provided students additional opportunities to make personal connections between course activities and their own career goals. "Connect" approaches to learning included structured in-class discussions, interactive dialogue with guest presenters, and project work.

\section{Learning Experiences}

The Taba model promotes the organization of content into learning experiences, which promotes the selection and organization of content considering planned learning objectives. ${ }^{10,17}$ Learning experiences refer to how the learning was delivered in the course in alignment with the predetermined teaching strategies (i.e. what specific activities students completed in and out of class). In-class learning experiences were jointly crafted by internal and external stakeholders. Each guest presenter was partnered with a faculty member for an 
assigned class period. Together they designed the learning activities students would engage in using the predetermined teaching strategies as a guide. Course readings, resources, and media content were identified by the faculty workgroup with input from pharmacy students and guest presenters. To optimize the learning experience for all students, an intentional effort was made to incorporate teaching materials that appealed to a variety of learning styles, including podcasts, TED Talks, policy briefs, as well as articles from the current peer-reviewed and lay literature. Guest presenters provided the real-world experience that helped bridge classroom learning and current rural pharmacy practice.

The fieldwork component of the learning experience was implemented as a longitudinal project. Students were assigned a rural community to assess in groups and spent a day in their assigned community engaging with patients and pharmacy preceptors to apply course content within real-world settings. A workgroup composed of five pharmacy students in their second year of the professional program was formed to develop unique learning experiences based on content items determined by the faculty workgroup. This student cohort collaborated with faculty workgroup members to design a series of templates that guided the semester-long rural community exploration project. This project included the following three learning experiences: 1) background research on an assigned rural community 2) rural community site visit and (3) interviews with pharmacists and patients from the community as well as the county health department.

The project templates were developed to guide students through the process of describing unique aspects of a rural community, identifying unmet healthcare needs, and developing a service to address a high priority need within the community. This project culminated in a group presentation describing these project components. An additional unique aspect of the longitudinal project was the opportunity to relate course readings and assignments to an actual rural location, where students have the opportunity to consider both quantitative data, as well as their qualitative lived experience during an on-site visit, to make a positive impact.

\section{Evaluative Measures}

Evaluation is considered within the Taba model to determine the effectiveness of curriculum design decisions. ${ }^{10,17}$ A subgroup of the faculty workgroup was tasked with developing and implementing a robust assessment plan that would provide formative feedback for future iterations of the course. The goal was to identify evaluative measures that would allow faculty to identify areas for improvement, as well as preliminary best practices related to course content, objectives, structure and delivery. To achieve this, the assessment plan was multifaceted and built around the core components of the Taba model. A map of the assessment plan, stratified by instructional components of the Taba model, is presented in Table 1 . Consistent with the collaborative spirit of the Taba model, evaluative measures were purposefully selected to assess the engagement of students, faculty, and external stakeholders to best understand their experience with the curriculum and opportunities for further improvement. This mixed-method approach included a combination of focus groups, questionnaires, reflections, faculty debriefing, student assignments, and course evaluations to better understand the elements of the course that were most impactful.

Using Curriculum Development Models in Pharmacy Education This case example provides a tangible illustration of course development through the integration of a curriculum model to design and evaluate the course content, structure, and delivery. While this case example describes application of the Taba model within a specific course at UW Madison, principles of curriculum models are widely applicable to the development of curricula both within and outside of pharmacy education. Although the Taba model was described in this manuscript, many other models support curriculum design. The first step in working with a curriculum model is selecting the most appropriate model for the wants and needs of the specific instructor(s) or program. Numerous additional curriculum theorists may inspire those seeking to advance curricula, including works by William Pinar that position teachers as facilitators to student self-discovery, ${ }^{23}$ to Elliot Eisner who reconsiders the placement of learning objectives in education, ${ }^{24}$ to Joseph Schwab who explores the complexity of curriculum development. ${ }^{25}$ The Understanding by Design model by Wiggins and McTighe serves as a more contemporary example of a curriculum design model. ${ }^{26}$ Understanding by Design emphasizes the backward design process, which involves considering the end goal of what students should understand or perform as an initial step to designing curricula.

To inform selection of a specific curriculum design model, it is helpful for instructors to perform a needs assessment at the outset to identify a model that best supports the opportunity for curriculum innovation. In the authors' case example, the immediate goal was for the model to guide instructors in designing, implementing and assessing the Topics in Rural Health course. A future goal is to apply the model in the development of the School's wider rural health curriculum. For this reason, the faculty selected a model that was adaptable across multiple uses and components of curriculum design. The non-linear nature of the Taba model allowed for this fluidity in application.

Once the desired use of the model has been determined, it is also helpful to identify pre-existing specifications or assumptions applying the design process to the individual program. The ability of models to support or allow for these aspects may dictate the model that is a good fit. For example, the Taba model was selected for the design of the rural pharmacy elective course because it provided a collaborative grassroots approach to curriculum design, which aligned with the faculty workgroup's 
desire to include both rural health stakeholders and student learners in the development process.

\section{Using the Taba Model}

There have been many lessons learned through incorporation of the Taba model within the Topics in Rural Health course. The most influential aspect of the Taba model was its emphasis on grass-roots approaches to curriculum design, which included promoting instructors, rather than school administrators, with the flexibility to determine content. Such an approach promotes opportunities for instructor engagement. Identification of course content and learning goals with input from external stakeholders was critical and provided the foundation for the design of learning experiences and assessment. The involvement of pharmacy students as members of the curriculum design team was critical, as it was students who provided some of the most valuable input on the delivery format of learning experiences.

Faculty involved in course design found the Taba model to provide needed context to explore competencies students should achieve throughout the course. In a sense, the Taba model served as a precursor to the backward design approach to developing a curriculum, which prioritizes learning goals before instructional methods. The Taba model was found to be especially useful in determining the learning goals that should be emphasized, given the model's emphasis on a teacher-driven curriculum and exploration of the topic and learners' needs based on discussions with key external and internal stakeholders. The Taba model served as a heavily inclusive approach to curriculum development, which in the literature has been discussed as a democratic teaching approach, involving grass-roots, collaborative efforts that are leveraged to identify specific learning objectives. ${ }^{2}$

Incorporation of the Taba model was also greatly beneficial in designing teaching strategies and learning experiences. The teaching strategies and experiences incorporated within the class were intentionally designed to emphasize the application and relatedness of fundamental course concepts to rural pharmacy practice, and in effect, to the students' future career interests. The Taba model's emphasis on critical thinking and application of concepts, rather than on rote memorization of facts, was informative as these experiences were developed. ${ }^{2}$ In many ways, the selection of the Absorb-Do-Connect learning framework, as a guide for stratification of course activities, also promoted emphasis on understanding, exploration, and application of content rather than on direct recall of information.

The process also allowed for the design of learning goals and instructional methods simultaneously, which promoted continuous revisions of teaching strategies, learning activities, and evaluative measures. Reflecting on the process of course development, the intentional incorporation of each aspect of the Taba model was time-intensive, but worth the additional effort. The outcome of this process allowed for a rural health course that was developed through widespread input and involvement from our broader rural health pharmacy team. Such an approach was invaluable to effective content development.

While the immediate assessment plan is focused on evaluating short-term outcomes to inform the next iteration of the course, a goal is to broaden the assessment in the future to focus on longer-term outcomes. This includes evaluating the impact of the entire rural health curriculum on student selection of rural APPE rotations, readiness for a career in rural healthcare, and eventual career decisions. An evaluation of longer-term outcomes will allow for continued modifications to the curriculum, with changes tracked and cataloged using Taba model elements to understand how the curriculum evolves over time. Elements deemed essential for course replication can then be clearly identified, and the impact of these course components evaluated throughout course implementation.

\section{Summary}

This manuscript presented a case study example of the use of a curriculum design model to develop a novel course emphasizing rural pharmacy practice. The presentation included the methods, intention, and purpose for use of the Taba model. Additional opportunities exist to add to the literature regarding the application of curriculum design models to promote the design of activities, courses, or programs.

Within pharmacy education, there is a tremendous opportunity for designers of activities, courses, and programs to apply concepts, frameworks, and models within the field of curriculum development to best prepare students. While the ACPE standards provide a guideline for what must be included in a curriculum, the field of curriculum design equips educators with the tools to move these curricular ideas into action while tailoring curriculum to the educator's school or college. How a new curriculum is designed, taught, and assessed will certainly impact the preparedness of our students, and as a result, may impact the effectiveness of our future pharmacists in practice. New curriculum opportunities in pharmacy education will continue to develop as our health care system adapts to novel technologies and areas of pharmacy practice. The exploration and application of curriculum design models provides opportunities to continue to innovate in our curriculum strategies, design, and delivery through developing evidencebased curricula with purpose.

Acknowledgements: Andrea Gray, DPH-4 and Matt Huppert, PharmD for participation in writing. John Eich, BA, Chris Barron, R.Ph, Bryant Schobert, PharmD, Michelle Farrell, PharmD, RPh, Julie Bartell, PharmD, CACP, BCACP for serving as stakeholders for curriculum development.

Conflicts of Interest: None

Funding/support: None 


\section{References}

1. Saritepeci M, Cakir H. The Effect of Blended Learning Environments on Student Motivation and Student Engagement: A Study on Social Studies Course. Eğitim ve Bilim. 2015;40(177). doi:10.15390/EB.2015.2592

2. Awidi IT, Paynter M. The impact of a flipped classroom approach on student learning experience. Comput Educ. 2019;128:269-283. doi: 10.1016/j.compedu.2018.09.013

3. Armbruster $P$, Patel $\mathrm{M}$, Johnson $\mathrm{E}$, et al. Active learning and student-centered pedagogy improve student attitudes and performance in introductory biology. CBE Life Sci Educ. 2009;8(3):203-213. doi: 10.1187/cbe.09-03-0025.

4. Caza A, Brower HH, Wayne JH. Effects of a holistic, experiential curriculum on business students' satisfaction and career confidence. Int J Manag Educ. 2015;13(1):75-83. doi: 10.1016/j.ijme.2015.01.006

5. Accreditation Council for Pharmacy Education. Accreditation standards and key elements for the professional program in pharmacy leading to the doctor of pharmacy degree, 2016. Available: https://www.acpeaccredit.org/pdf/Standards2016FINAL.pdf. Accessed February 20, 2020.

6. Hewitt T. Understanding and Shaping Curriculum: What We Teach and Why. Thousand Oaks, California: Sage Publications; 2006. doi: 10.4135/9781452204277

7. Kysilka ML. Critical Times in Curriculum Thought: People, Politics, and Perspectives. Charlotte, NC: Information Age Publishing; 2011.

8. Tyler, R. Basic Principles of Curriculum and Instruction. Chicago, IL: The University of Chicago Press; 2013.

9. Lunenburg FC. Curriculum development: inductive models. Schooling. 2011;2(1):1-8.

10. Papakitsos EC. The Application of Systems Methodology to Curriculum Development in Higher Education. SPG Biomed. 2016;1(1):1-9. doi: 10.11648/j.her.20160101.11

11. Baron KA. Changing to Concept-Based Curricula: The Process for Nurse Educators. Open Nurs J.

2017;11:277-287. doi: $10.2174 / 1874434601711010277$

12. Kyriacos, U. Developing critical thinking skills. Curationis. 1992;15(3):48-51.

13. Aydın B, Melek M, Alan B, Sağlam S. Combining the old and the new: Designing a curriculum based on the taba model and the global scale of English. J Lang Ling Stud. 2017;13(1):304-320.

14. Namubiru P, Ezati B, Biasaso R, et al. Migrating a professional field of study in a multi-institutional partnership: facilitators' experience in the competence-based curriculum development process. Tun High Ed. doi: 10.18543
15. WisContext. Putting Rural Wisconsin On The Map. https://www.wiscontext.org/putting rural-wisconsinmap. Accessed April 6, 2019.

16. Taba H. Curriculum development; Theory and Practice. New York, NY: Harcourt, Brace \& World; 1962.

17. Laanemets UL, Katrin K. The Taba-Tyler Rationales. J Amer Assoc Adv Curr Stud. 2013;9:1-12. doi: 10.14288/jaaacs.v9i2.187723

18. Hunkins FP, Hammill PA. Beyond Tyler and Taba: Reconceptualizing the Curriculum Process. Peabody J Educ. 1994;69(3):4-18. doi: 10.1080/01619569409538774

19. Wallen NE, Durkin MC, Fraenkel JR, McNaughton AJ, Sawin El. The Taba curriculum development project in social studies. San Francisco, CA: US Department of Health, Education, and Welfare; 1969.

20. Carl, AE. Teacher Empowerment Through Curriculum Development: Theory Into Practice. Cape Town, South Africa: Juta and Company Ltd; 2009.

21. Horton W. E-Learning by Design. San Francisco, CA: Wiley; 2011.

22. Pinar W. Curriculum toward New Identities. New York, NY: Routledge; 2013.

23. Eisner EW, Eisner EW. Cognition and Curriculum Reconsidered. New York, NY: Teachers College Press;1994.

24. Schwab JJ. The Practical: A Language for Curriculum. Sch Rev. 78:1-23.

25. Wiggins GP, McTighe J. Understanding by Design. $2^{\text {nd }}$ ed. Alexandria, VA: Association for Supervision and Curriculum Development; 2005. 
Table 1. Topics in Rural Health Course Assessment Plan Stratified by Taba Model Component

\begin{tabular}{|c|c|c|}
\hline $\begin{array}{l}\text { Taba Model Instructional } \\
\text { Components }\end{array}$ & Questions Considered & Evaluative Measures \\
\hline Content & $\begin{array}{l}\text { Did course content align with } \\
\text { contemporary rural health practice and } \\
\text { wants and needs of stakeholders? (ie, } \\
\text { interprofessional collaboration, broad } \\
\text { clinical skillset, adaptability, creative } \\
\text { thinking and innovation) }\end{array}$ & $\begin{array}{ll}\text { - } & \text { Stakeholder surveys } \\
\text { - } & \text { End of semester faculty } \\
\text { - } & \text { debriefing } \\
\text { Student focus groups }\end{array}$ \\
\hline Learning Objectives & $\begin{array}{l}\text { Did students demonstrate achievement of } \\
\text { desired learning outcomes? }\end{array}$ & $\begin{array}{l}\text { - } \quad \text { Performance on course } \\
\text { assignments } \\
\text { - } \quad \text { Pre and post student } \\
\text { surveys }\end{array}$ \\
\hline Teaching Strategies & $\begin{array}{l}\text { Did teaching strategies engage students } \\
\text { and connect course content/activities to } \\
\text { rural pharmacy practice? }\end{array}$ & $\begin{array}{ll}\text { - } & \text { In-class student } \\
\text { - } & \text { engagement } \\
\text { - } & \text { Student reflections } \\
\text { - } & \text { Sourse evaluations }\end{array}$ \\
\hline Learning Experiences & $\begin{array}{l}\text { Did course activities promote student } \\
\text { learning and facilitate achievement of } \\
\text { learning objectives? }\end{array}$ & $\begin{array}{ll}\text { - } & \text { Performance on course } \\
\text { - } & \text { Student reflections } \\
\text { - } & \text { Student focus groups } \\
\text { - } & \text { Course evaluations }\end{array}$ \\
\hline Evaluative Measures & $\begin{array}{l}\text { Did the assessment plan provide } \\
\text { appropriate feedback to inform future } \\
\text { iterations of the course? } \\
\text { Are students signing up for a greater } \\
\text { number of rural APPEs? } \\
\text { Do students have greater intention to } \\
\text { pursue a career in rural pharmacy } \\
\text { practice? }\end{array}$ & $\begin{array}{l}\text { - End of semester faculty } \\
\text { debriefing }\end{array}$ \\
\hline
\end{tabular}

Figure 1. Application of Taba Model to Topics in Rural Health Course Design ${ }^{11}$

\section{Internal Stakeholders: Students}

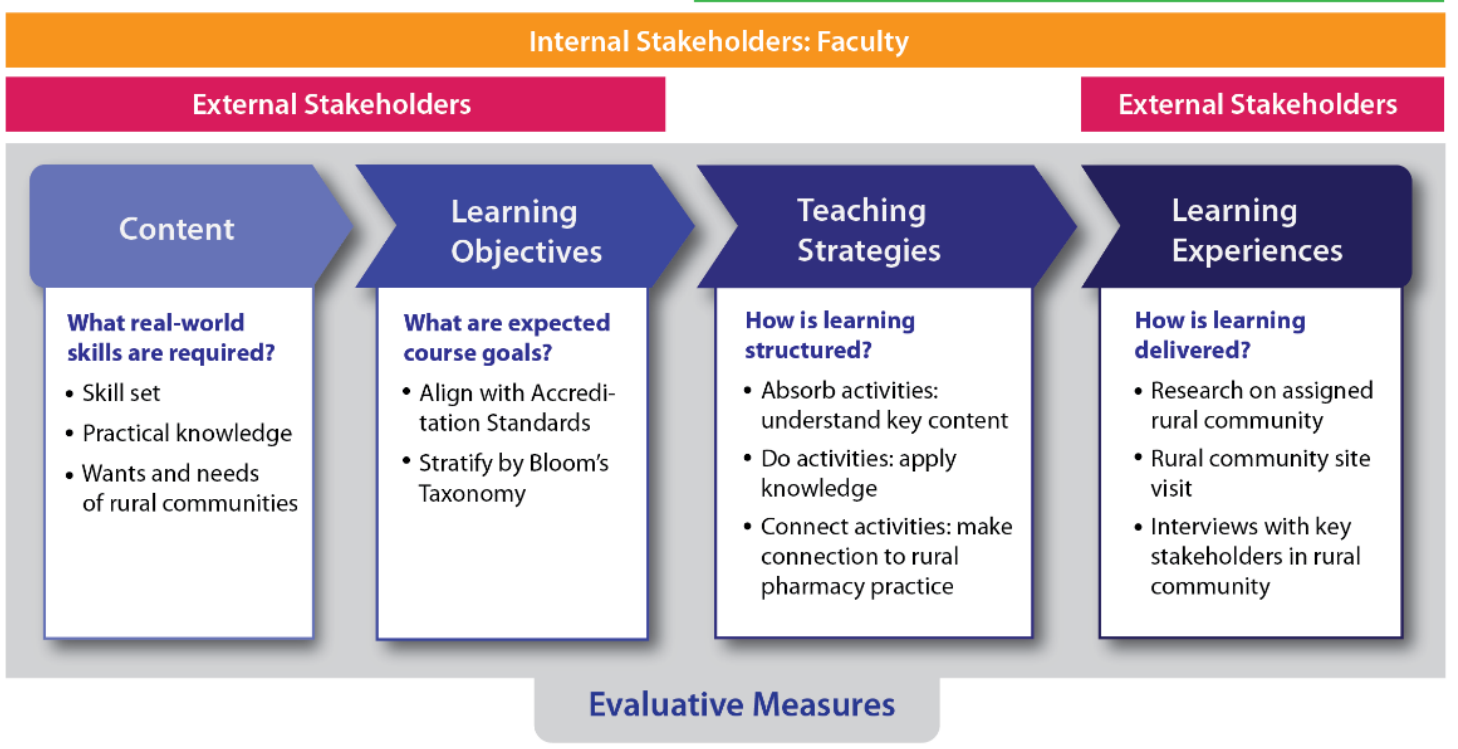

